Institute of $\mathbf{F}_{\text {ood and }} \mathbf{A}_{\text {gricultural }} \mathbf{S}_{\text {ciences }}$

\title{
Rearing Copepods for Mosquito Control ${ }^{1}$
}

\author{
Jorge Rey and Sheila O'Connell ${ }^{2}$ \\ Introduction
}

Copepods are tiny aquatic crustaceans (shrimp, crabs lobster, and relatives) that are widespread in both fresh and salt water habitats. They are voracious predators of mosquito larvae and as such, can be used to control mosquito production from water holding areas. Copepod cultures are relatively easy to maintain, but getting the cultures started requires some effort and time. Also, some equipment that may not be readily available to the average home owner (such as a dissecting microscope) can make life a lot easier.

For effective mosquito control with copepods, it is essential that you know where the mosquitoes are breeding. Just because you see larvae in one place does not mean that that is your major mosquito problem, so if you eliminate breeding there you may not see a significant change in adult mosquito populations. Most mosquito control agencies spend a great deal of time, manpower, and money doing "surveillance" to identify their major mosquito problems areas. To complicate matters, these "hot spots" can change with time and physical conditions.

\section{Field Collection}

Copepods for culture start-up can be collected from ponds ditches and other standing water sources. They can be collected by quickly dipping a suitable container (a standard mosquito dipper works well -Figure 1)

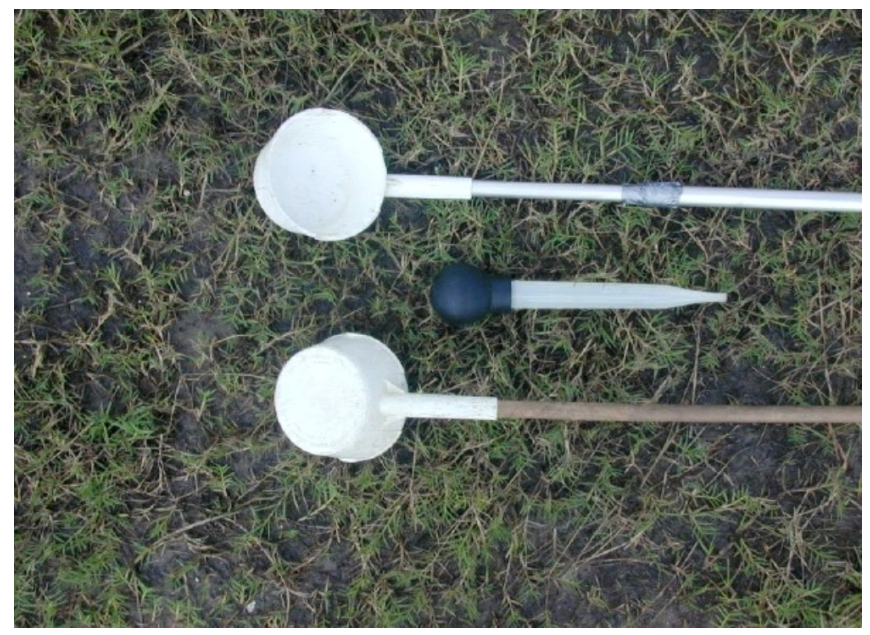

Figure 1. Mosquito dippers.

in the water, particularly near submerged vegetation. After dipping, slowly pour out $2 / 3$ of the water in the container, and look at the remaining water for signs of the copepods (Figure 2). Even

1. This document is ENY-697, one of a series of the Entomology and Nematology Department, Florida Cooperative Extension Service, Institute of Food and Agricultural Sciences, University of Florida. Original publication date Februaru, 2004. Visit the EDIS Web Site at http://edis.ifas.ufl.edu.

2. Jorge R. Rey, professor, Sheila O'Connell, biological scientist, Entomology and Nematology Department, Florida Medical Entomology Laboratory, Vero Beach, Cooperative Extension Service, Institute of Food and Agricultural Sciences. University of Florida, Gainesville, FL 32611

The use of trade names in this publication is solely for the purpose of providing specific information. UF/IFAS does not guarantee or warranty the products named, and references to them in this publication does not signify our approval to the exclusion of other products of suitable composition. 
though thay are small, they can be seen swimming in the collection vessel. If copepods are present, quickly pour the contents into a clean container, label, and cap securely.

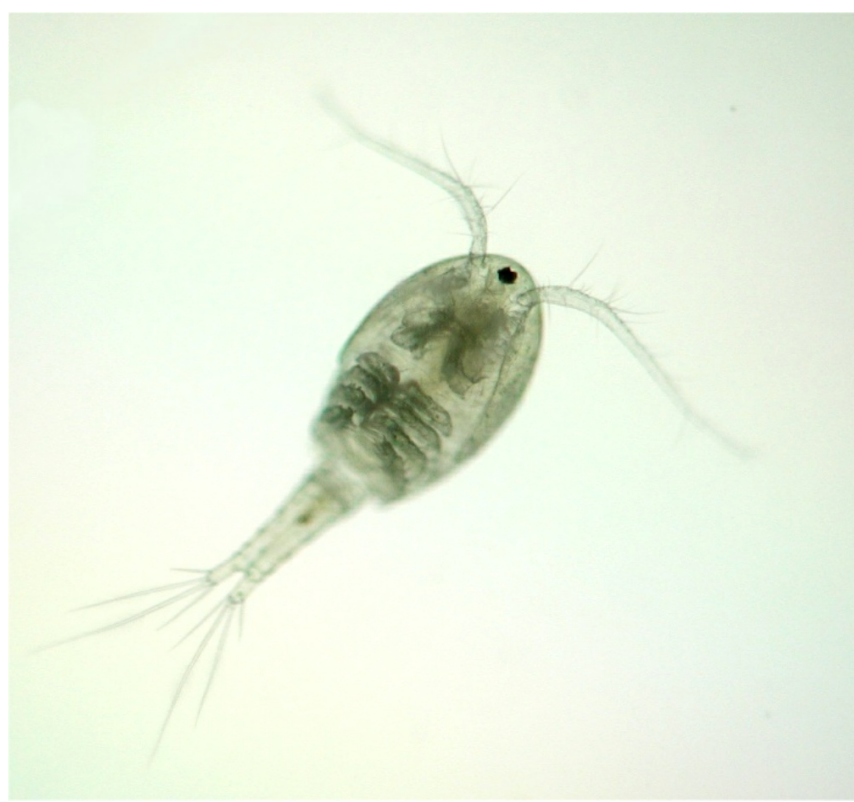

Figure 2. Adult copepod.

Copepods can also be collected by passing water through two in-line sieves, either by pumping or by scooping water with a bucket and pouring through the strainers. The top sieve can be an ordinary kitchen strainer; its function is to capture large debris that may be present in the water. Copepods will be captured in the second sieve which should be set-up as follows: Obtain a piece of $200 \mu \mathrm{m}$ mesh netting large enough to cover a second strainer; push in the middle to roughly the shape of the strainer bowl and secure the edges to the strainer with a rubber band (Figures $3 \& 6$ ).

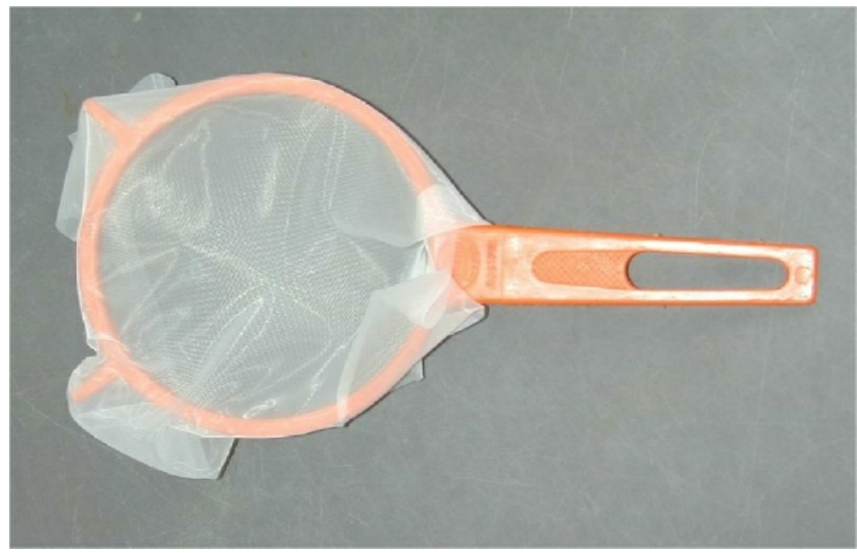

Figure 3. Collection strainer.
After filtering through this set-up, either remove the netting and invert in a container of clean de-chlorinated water, or turn the second sieve set-up upside down over a clean container and rinse with clean de-chlorinated water from a squirt bottle. Add water to the collection containers as needed, cover and label.

\section{Start-up Cultures}

Cultures for mosquito control should consist of single species, to assure consistency once an appropriate species is selected (see below). Gravid females can be easily recognized because they carry their eggs externally on both sides of their bodies (Figure 4).

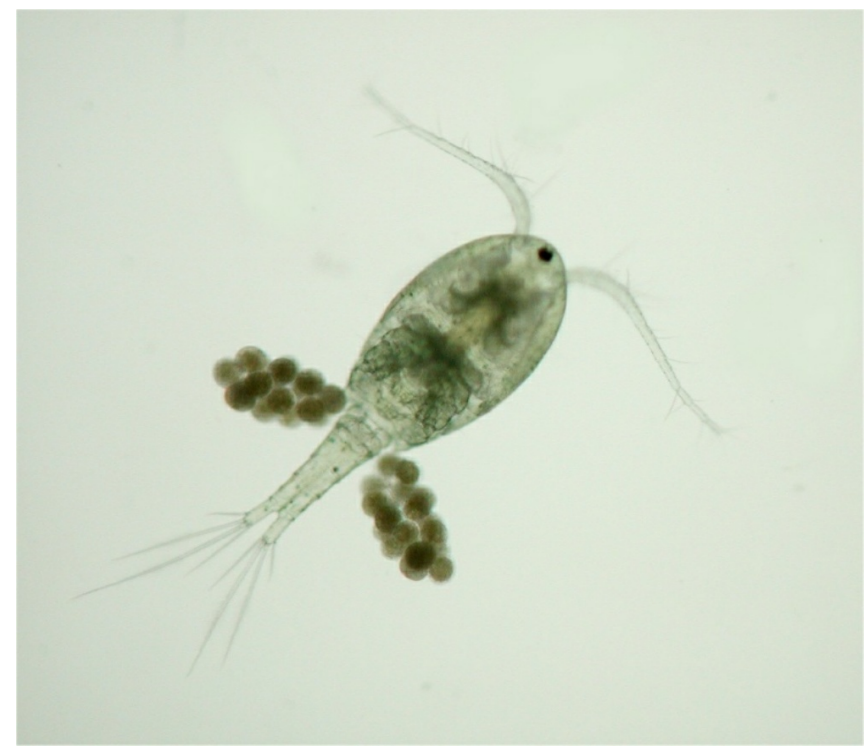

Figure 4. Gravid female copepod.

To start a pure culture, set up several small containers (disposable food containers work well) about 3/4 full of de-chlorinated water and introduce a single gravid female in each (Figure 5).

This is best done by picking up the female with a pipette, depositing it in a shallow dish with de-chlorinated water and then picking her up again and placing her in the culture container. This minimizes the chances of unintentionally introducing more than one species into the culture containers.

Water containing chlorine can be de-chlorinated by letting it sit in open containers for several days, by passing through an industrial charcoal filter, or by 


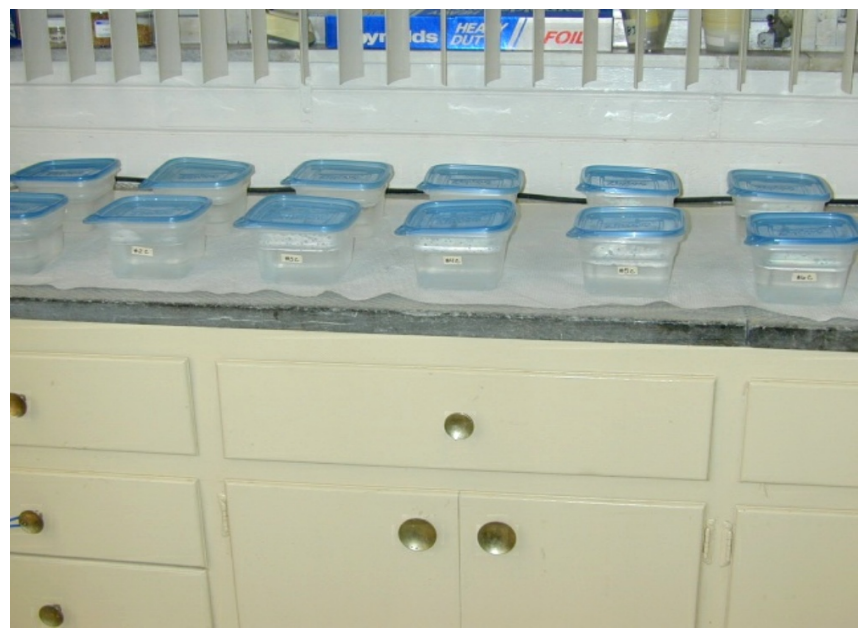

Figure 5. Culture start-up containers.

treating with chemicals (e.g. sodium thiosulfate) available at most aquarium stores.

Copepods can be reared in pools (plastic kiddie pools) garbage cans or other suitable containers. We have found that aquaria and similar vessels with glass (clear) sides are not very good for rearing copepods. Below we will describe the procedure using plastic pools, but the steps are the same regardless of the container used.

We recommend that at least two pools (more if possible) be set-up and maintained at all times. Fill the pools with approximately $80 \mathrm{~L}$ of water from a hose or other suitable source. If the water contains chlorine, let it sit in the pools for approximately five to seven days to allow any chlorine in the water to dissipate. It is always a good idea to test the water in smaller containers with a few copepods to see if the copepods will survive and reproduce in it. Introduce several dozen adults and see if immatures (nauplii, Figure 6) are produced. Continue to monitor these containers to determine if the copepod population is growing after 2-3 weeks.

Once you are satisfied that the water that you are using will sustain the copepods, introduce at least 200 adults from the startup dishes into each of the rearing pools and place a standard aquarium aerator in each pool. Add approximately $1000 \mathrm{ml}$ of Paramecium culture (see below) and 100 grains of wheat grain. The copepods will readily feed on the Paramecia, and the Paramecia on the wheat grain. Place the pools so that they receive light (natural or artificial) for at least part of the day, but away from direct sun.
Copepods are very hard to see at the beginning of the set up due to the low density. Monitor the pools regularly (every one or two days) until you are satisfied that the cultures are viable, that immatures are being produced and that copepod numbers are increasing. One way to do this is to take several $500-1000 \mathrm{ml}$ water samples from the pools and checking for nauplii, gravid females, and overall copepod density. When density increases copepods can be seen with the naked eye throughout the pool, swimming \& resting. At this point, monitoring the cultures every 1-2 weeks should be sufficient.

\section{Pool Maintenance}

As the wheat seed decomposes, some will start floating to the surface of the water and should be removed. This can be done by scooping with an $800 \mu \mathrm{m}$ sieve and discarding. Sieves can be made by cutting a large hole on a large plastic lid and gluing the desired size mesh tightly to cover the hole. Some examples of homemade sieves are shown in Figure 6.

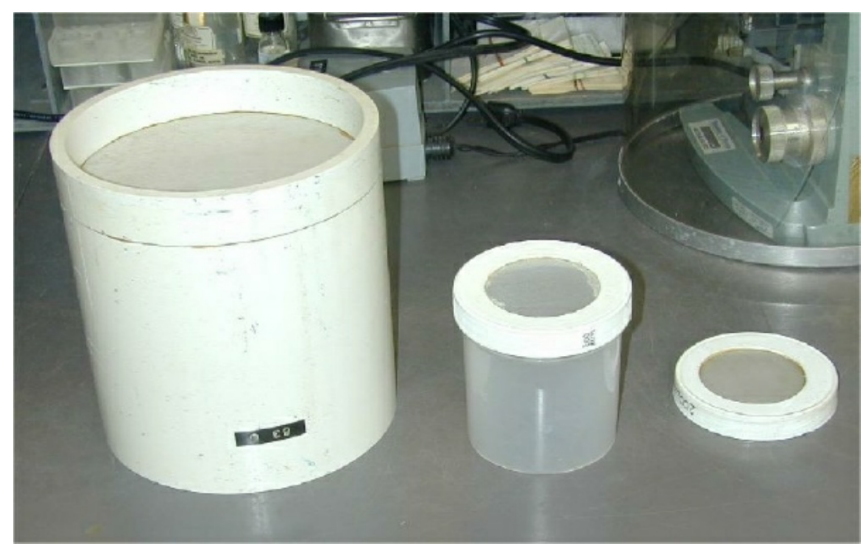

Figure 6. Homemade sieves

Pools should be emptied and cleaned at least once yearly. This is typically done in late spring to avoid extreme temperatures which could possible increase the chance of mortality. Water is siphoned out of the pool and through a $200 \mu \mathrm{m}(0.02 \mathrm{~cm})$ mesh screen. The contents collected (adult copepods, copepodites, nauplii, Paramecium, and wheat seed) are then separated using a $800 \mu \mathrm{m}(0.08 \mathrm{~cm})$ mesh sieve to eliminate the wheat seed. The reduced 
volume of water containing the copepods is placed in the pool per the "initial set-up" instructions. Do not clean all of your pools at once. Make sure that the cultures are thriving after cleaning a pool, before your clean the next one.

\section{Paramecium Cultures}

Stock material for Paramecium cultures are inexpensive and can be purchased from any biological supply store (e.g., Carolina Biological http://www.carolina.com/). Add $25 \mathrm{ml}$ of the Paramecium caudatum start culture to 1 gallon of spring water (acclimate the Paramecia to the spring water temperature before adding). Then add approximately 12 grains of wheat seed per gallon of culture and a small pinch of yeast. Plastic milk cartons ( 1 gallon or $1 / 2$ gallon) work well for culturing Paramecium, as well as 5 gallon water jugs. Wait about two weeks (at room temperature) before using. Save about $500 \mathrm{ml}$ of each jug, refill with water and add wheat seed and yeast as before to start a new culture. Once a year, purchase new start-up cultures and process as before.

\section{Rearing Notes}

- If copepods are cultured outside, they need to be covered and at least $3 \mathrm{ft}$. off of the ground; ostracods and other organisms will invade and dominate copepod population.

- Aquaria or similar vessels are not ideal for copepod rearing.

- It is a good idea to set up several pools and to maintain additional cultures in smaller containers at a separate location so that new cultures can be started in case of loss of original cultures.

\section{Identification and Predation Efficiency Testing}

Ideally, copepods captured in the field should be identified to species before using, however, this is very difficult to do and requires an expert taxonomist for reliable identification. An interactive key to major copepod groups can be found at: http://www.glsc.usgs.gov/greatlakescopepods/
If specific identifications are not made initially, it is absolutely essential that cultures remain pure (single species), and that one continue to attempt to have the animals identified by an expert.

Before a time investment is made to rear copepods for mosquito control, you should test the ability of the particular species that you have to accomplish this. Not all copepods are effective mosquito control agents, and some are better than others. To test for predation rates, you will need to obtain first instar (newly hatched) mosquito larvae. The easiest way to do this is to obtain mosquito eggs from a local mosquito control agency and hatch them just prior to the experiment. This usually involves simply submerging the eggs in dechlorinated water. Place 500 newly hatched larvae in a $200-500 \mathrm{ml}$ container half full with dechlorinated water and add 8-10 adult copepods. Let sit for 24 hrs. and then count how many larvae are left. For effective mosquito control, a single copepod should be able to consume approximately 30 first instar larvae per day or more. Ideally, this experiment should be replicated several times. 